\section{Space structures for sports buildings}

Tien T. Lan and Yuan Zhilian (eds)

Elsevier Applied Science Publishers, The Netherlands, 1987

Collected in this volume are 76 papers presented at the IASS symposium held in Beijing. Peoples Republic of China on 27-30 October 1987, organized by the China Civil Engineering Society. The papers were selected by the organizers as representing topics pertinent to the application of spatial structures to sports buildings. The papers are grouped as follows

- Worldwide review

- General problems

- Continuous shells

- Space trusses

- Reticulated shells

- Cable structures

- Membrane structures lacks somewhat in unity, the quality of the papers varies and some important topics are not covered. The excellent 'General review', by Makowski, is restricted (by design) to braced space structures. Equivalent reviews in the fields of shells, cable structures and membranes are not given.

The second topic-general problems - contains some interesting examples of recent realizations, from several countries, and discussion of several failures. Also covered in this rather broad part of the book are questions of conceptual design and theoretical analysis.

In the remaining parts of the publication the papers are grouped as previously noted. It may be of interest to point out that the number of contributions in the area of continuum shells (10 papers) is rather small compared with the currently fashionable reticulated shells (20 papers), and cable and membrane structures (24 papers).

In summary, parts of this interesting volume may prove useful as a reference for designers and researchers in the field.

Avelino Samartin

As is typical of proceedings of symposia, the book covers a wide range of subjects, of interest to diverse groups such as engineers, builders, architects and researchers. At the same time, the book 